This is the author's final, peer-reviewed manuscript as accepted for publication. The publisher-formatted version may be available through the publisher's web site or your institution's library.

\title{
The NO donor sodium nitroprusside: evaluation of skeletal muscle vascular and metabolic dysfunction
}

Daniel M. Hirai, Steven W. Copp, Scott K. Ferguson, Clark T. Holdsworth, Timothy I. Musch, David C. Poole

\section{How to cite this manuscript}

If you make reference to this version of the manuscript, use the following information:

Hirai, D. M., Copp, S. W., Ferguson, S. K., Holdsworth, C. T., Musch, T. I., \& Poole, D. C. (2013). The NO donor sodium nitroprusside: Evaluation of skeletal muscle vascular and metabolic dysfunction. Retrieved from http://krex.ksu.edu

\section{Published Version Information}

Citation: Hirai, D. M., Copp, S. W., Ferguson, S. K., Holdsworth, C. T., Musch, T. I., \& Poole, D. C. (2013). The NO donor sodium nitroprusside: Evaluation of skeletal muscle vascular and metabolic dysfunction. Microvascular Research, 85(1), 104-111.

Copyright: (c) 2012 Elsevier Inc.

Digital Object Identifier (DOI): doi:10.1016/j.mvr.2012.11.006

Publisher's Link: http://www.sciencedirect.com/science/article/pii/S0026286212002026

This item was retrieved from the K-State Research Exchange (K-REx), the institutional repository of Kansas State University. K-REx is available at http://krex.ksu.edu 
The NO donor sodium nitroprusside: evaluation of skeletal muscle vascular and metabolic dysfunction

Daniel M. Hirai ${ }^{1}$, Steven W. Copp ${ }^{1}$, Scott K. Ferguson ${ }^{1,2}$, Clark T. Holdsworth ${ }^{1,2}$, Timothy I. Musch $^{1,2}$, David C. Poole ${ }^{1,2}$

Departments of ${ }^{1}$ Anatomy \& Physiology, and ${ }^{2}$ Kinesiology, Kansas State University, Manhattan, Kansas, USA

Running Title: Sodium nitroprusside and skeletal muscle function

\section{Corresponding author:}

David C. Poole

Department of Anatomy and Physiology

College of Veterinary Medicine

Kansas State University

Manhattan, KS 66506-5802

Tel.: 785-532-4529

Fax: 785-532-4557

E-mail: poole@vet.ksu.edu 


\begin{abstract}
The nitric oxide (NO) donor sodium nitroprusside (SNP) may promote cyanide-induced toxicity and systemic and/or local responses approaching maximal vasodilation. The hypotheses were tested that SNP superfusion of the rat spinotrapezius muscle exerts 1) residual impairments in resting and contracting blood flow, oxygen utilization $\left(\dot{V}_{2}\right)$ and microvascular $\mathrm{O}_{2}$ pressure $\left(\mathrm{PO}_{2} \mathrm{mv}\right)$; and 2) marked hypotension and elevation in resting $\mathrm{PO}_{2} \mathrm{mv}$. Two superfusion protocols were performed: 1) Krebs-Henseleit (control 1), SNP (300 $\mu \mathrm{M}$; a dose used commonly in superfusion studies) and Krebs-Henseleit (control 2), in this order; 2) 300 and $1200 \mu \mathrm{M} \mathrm{SNP} \mathrm{in}$ random order. Spinotrapezius muscle blood flow (radiolabeled microspheres), $\dot{\mathrm{V}} \mathrm{O}_{2}$ (Fick calculation) and $\mathrm{PO}_{2} \mathrm{mv}$ (phosphorescence quenching) were determined at rest and during electrically-induced $(1 \mathrm{~Hz})$ contractions. There were no differences in spinotrapezius blood flow, $\dot{\mathrm{V}} \mathrm{O}_{2}$ or $\mathrm{PO}_{2} \mathrm{mv}$ at rest and during contractions pre- and post-SNP condition (control 1 and control $2 ; p>0.05$ for all). With regard to dosing, SNP produced a graded elevation in resting $\mathrm{PO}_{2} \mathrm{mv}$ $(p<0.05)$ with a reduction in mean arterial pressure only at the higher concentration $(p<0.05)$. Contrary to our hypothesis, skeletal muscle superfusion with the NO donor SNP $(300 \mu \mathrm{M})$ improved microvascular oxygenation during the transition from rest to contractions $\left(\mathrm{PO}_{2} \mathrm{mv}\right.$ kinetics) without precipitating residual impairment of muscle hemodynamic or metabolic control or compromising systemic hemodynamics. These data suggest that SNP superfusion $(300 \mu \mathrm{M})$ constitutes a valid and important tool for assessing the functional roles of NO in resting and contracting skeletal muscle function without incurring residual alterations consistent with cyanide accumulation and poisoning.
\end{abstract}


Abbreviations: FDA, Food and Drug Administration; MAP, mean arterial pressure; NO, nitric oxide; SNP, sodium nitroprusside; $\dot{Q} \mathrm{O}_{2}$, oxygen delivery; $\dot{\mathrm{V}} \mathrm{O}_{2}$, oxygen utilization; $\mathrm{PO}_{2} \mathrm{mv}$, microvascular oxygen pressure

Keywords: blood flow; kinetics; microcirculation; microvascular partial pressure of oxygen; nitric oxide; oxygen uptake; superfusion 


\section{Introduction}

Nitric oxide (NO) and its derivatives are important modulators of skeletal muscle hemodynamic and metabolic control (Stamler and Meissner, 2001). During the transition from rest to contractions, NO contributes to the increase in skeletal muscle oxygen delivery $\left(\dot{Q} O_{2}\right)$ mainly via endothelium-dependent vasodilation (Hirai et al., 1994; Schrage et al., 2004) and the inertia of oxidative metabolism (i.e., finite $\dot{V} \mathrm{O}_{2}$ kinetics) via inhibition of mitochondrial respiration (Jones et al., 2003; Kindig et al., 2002). Accordingly, alterations in NO levels within skeletal muscle impact profoundly the dynamic $\dot{Q} \mathrm{O}_{2} / \dot{V} \mathrm{O}_{2}$ matching (and thus the $\mathrm{O}_{2}$ pressure within the microvasculature; $\mathrm{PO}_{2} \mathrm{mv}$ ) during metabolic transitions in health and disease (Ferreira et al., 2006a; Ferreira et al., 2006b; Hirai et al., 2012; Hirai et al., 2010). Pharmacological agents that release NO therefore represent valuable research tools for assessing the mechanistic roles of NO in physiology and pathophysiology (Ignarro et al., 2002).

The NO donor sodium nitroprusside (SNP; sodium pentacyanonitrosylferrate, $\left.\mathrm{Na}_{2}\left[\mathrm{Fe}(\mathrm{CN})_{5}(\mathrm{NO})\right]\right)$ is a potent vasodilator used widely in both clinical and research arenas (human and animal models; Friederich and Butterworth, 1995; Ignarro et al., 2002). SNP has rapid onset and reversibility of action and produces vasodilatory effects that resemble closely those of endogenous, endothelium-derived NO (Miller et al., 2004; Wanstall et al., 2001). However, because SNP metabolism releases cyanide and may promote oxidative stress, its usage carries the risk of toxicity with prolonged administration and/or high dosages (Friederich and Butterworth, 1995; Ignarro et al., 2002; Pettersen and Cohen, 1993; Rao et al., 1991; Rauhala et al., 1998). Specifically, cyanide-induced toxicity is associated with inhibition of mitochondrial oxidative phosphorylation (Pettersen and Cohen, 1993; Way, 1984) and impairments in vasomotor control (and consequently blood flow and/or mean arterial pressure regulation; 
Ignarro et al., 1986) which are expected to result in $\dot{Q} O_{2} / \dot{V} O_{2}$ mismatch. These concerns led to reports recommending SNP usage to be curtailed or even discontinued (Rauhala et al., 1998; Robin and McCauley, 1992; Varon and Marik, 2003) and the Food and Drug Administration (FDA) approving a label for clinical SNP usage in 1991 that highlights its potential toxicity due to cyanide accumulation (Nightingale, 1991).

The purpose of the present investigation was to determine whether SNP superfusion disrupts the functional integrity of skeletal muscle hemodynamic and/or metabolic control at rest and during contractions. It was hypothesized that skeletal muscle superfusion with SNP (300 $\mu \mathrm{M}$, a concentration of the order employed in our and other laboratories; Behnke and Delp, 2010; Boegehold, 1992; Didion and Mayhan, 1997; Ferreira et al., 2006a; Ferreira et al., 2006b; Hirai et al., 2012; Hirai et al., 2010; Lash and Bohlen, 1997; Muller-Delp et al., 2002; Padilla et al., 2010; Saito et al., 1994; Sato et al., 2008; Trott et al., 2009) would exert residual (i.e., postwashout) impairment of skeletal muscle blood flow, $\dot{\mathrm{VO}}{ }_{2}$ and $\mathrm{PO}_{2} \mathrm{mv}$ during the transition from rest to contractions and responses consistent with or approximating maximal vasodilation (i.e., a saturation dose accompanied by marked hypotension and elevation in resting $\mathrm{PO}_{2} \mathrm{mv}$ ). 


\section{Methods}

A total of 27 male Sprague-Dawley rats (4-5 months old; Charles Rivers Laboratories, Boston, MA, USA) were utilized in the present investigation. All experimental procedures followed guidelines established by the National Institutes of Health and were approved by the Institutional Animal Care and Committee of Kansas State University. Rats were housed in accredited facilities and maintained on a 12:12 h light-dark cycle with food and water available ad libitum.

\section{Surgical procedures}

On the day of data collection, rats were anesthetized initially with a $5 \%$ isoflurane- $\mathrm{O}_{2}$ mixture and maintained on 2-3\% isoflurane- $\mathrm{O}_{2}$ (Butler Animal Health Supply, Dublin, OH, USA). The right carotid and caudal (tail) arteries were cannulated (PE-10 connected to PE-50; Intra-Medic Tubing, Clay Adams Brand, Sparks, MD, USA) for continuous measurements of mean arterial pressure (MAP; Digi-Med BPA model 200, Louisville, KY, USA), infusion of the phosphorescent probe palladium meso-tetra (4-carboxyphenyl) porphyrin dendrimer (R2; 15 mg/kg; Oxygen Enterprises, Philadelphia, PA, USA) and arterial blood sampling. Blood samples were taken at the end of each experimental protocol for determination of arterial blood gases and systemic hematocrit (Nova Stat Profile M, Waltham, MA, USA). Anesthetized rats were kept on a heating pad to maintain core temperature at $\sim 37-38^{\circ} \mathrm{C}$ (measured via rectal probe).

Following catheter placement procedures, rats were transitioned progressively to pentobarbital sodium (administered i.a. to effect) and monitored frequently via the toe-pinch and blink reflexes with anesthesia supplemented as necessary. Overlying skin and fascia were then reflected carefully from the mid-dorsal region of the rat to expose the left and right 
spinotrapezius muscles. Stainless steel electrodes were sutured to the rostral (cathode) and caudal (anode) regions of the right spinotrapezius muscle for electrically-induced contractions. Exposed muscles were moistened frequently during the surgical preparation via superfusion of KrebsHenseleit bicarbonate-buffered solution $\left(4.7 \mathrm{mM} \mathrm{KCl}, 2.0 \mathrm{mM} \mathrm{CaCl}_{2}, 2.4 \mathrm{mM} \mathrm{MgSO}_{4}, 131 \mathrm{mM}\right.$ $\mathrm{NaCl}$ and $22 \mathrm{mM} \mathrm{NaHCO}_{3} ; \mathrm{pH}=7.4$; equilibrated with $5 \% \mathrm{CO}_{2}$ and $95 \% \mathrm{~N}_{2}$ at $\sim 38^{\circ} \mathrm{C}$ ) whereas surrounding tissue was covered with Saran wrap (Dow Brands, Indianapolis, IN, USA). Previous reports from our laboratory demonstrate that these surgical procedures do not impair the microvascular integrity and responsiveness of the rat spinotrapezius muscle (Bailey et al., 2000).

\section{Experimental protocols}

Rats were assigned randomly to different groups to examine whether the SNP superfusion concentration of the order employed in our and other laboratories (300 $\mu \mathrm{M}$; Behnke and Delp, 2010; Boegehold, 1992; Didion and Mayhan, 1997; Ferreira et al., 2006a; Ferreira et al., 2006b; Hirai et al., 2012; Hirai et al., 2010; Lash and Bohlen, 1997; Muller-Delp et al., 2002; Padilla et al., 2010; Saito et al., 1994; Sato et al., 2008; Trott et al., 2009) evokes residual impairments in skeletal muscle hemodynamic and/or metabolic function (Group A; $\mathrm{n}=15$ ) or responses consistent with maximal vasodilation (Group $B ; \mathrm{n}=12$ ). Chemicals and drugs were purchased from Sigma-Aldrich (St. Louis, MO, USA) and concentrations were chosen based on previous investigations from our and other laboratories (Behnke and Delp, 2010; Boegehold, 1992; Didion and Mayhan, 1997; Ferreira et al., 2006a; Ferreira et al., 2006b; Hirai et al., 2012; Hirai et al., 2010; Lash and Bohlen, 1997; Muller-Delp et al., 2002; Padilla et al., 2010; Saito et al., 1994; Sato et al., 2008; Trott et al., 2009). Specifically, the $300 \mu \mathrm{M}$ SNP superfusion concentration was titrated to evoke consistent alterations in $\mathrm{PO}_{2} \mathrm{mv}$ without compromising 
systemic hemodynamics (i.e., a decrease in MAP below $70 \mathrm{mmHg}$ at any time; Behnke et al., 2006; Ferreira et al., 2006b). All solutions were kept at $\sim 38^{\circ} \mathrm{C}$. In order to minimize SNP photodecomposition and potential cyanide release (Bisset et al., 1981; Butler et al., 1987), SNP solutions were protected from light sources by covering containers and syringes with aluminum foil and, as a mandate for $\mathrm{PO}_{2} \mathrm{mv}$ measurements using phosphorescence quenching, performing experiments in a darkened room.

Group A. Three contraction bouts were performed to examine potential impairment of spinotrapezius muscle hemodynamic and metabolic function with the relevant SNP superfusion (300 $\mu \mathrm{M}$; see Fig. 1). The left and right spinotrapezius muscles were superfused in the following order: control 1 (5 ml Krebs-Henseleit), SNP (5 ml of a $300 \mu \mathrm{M}$ SNP solution), control 2 (5 ml Krebs-Henseleit). Muscles were superfused with each solution (average flow rate of $\sim 1.5$ $\mathrm{ml} / \mathrm{min}$ ) for a total time of $3 \mathrm{~min}$, followed by a $3 \mathrm{~min}$ incubation period (i.e., no superfusion) to allow resting MAP and muscle $\mathrm{PO}_{2} m v$ to stabilize. Subsequently, electrical stimulation $(1 \mathrm{~Hz}, \sim 7$ V, 2 ms pulse duration) of the right spinotrapezius muscle was evoked via a Grass stimulator (model s48, Quincy, MA, USA) for 3 min and an $\sim 20$ min recovery period was undertaken before the next condition was initiated (stimulation parameters held constant). This stimulation protocol evokes an $\sim 4-5$ fold increase in blood flow along with $\sim 6-7$ fold increase in metabolic rate (i.e., $\sim 30 \%$ of maximum spinotrapezius $\dot{V} \mathrm{O}_{2}$ ) above resting with either minor or no changes in blood $\mathrm{pH}$ consonant with moderate intensity exercise (current results and Behnke et al., 2002; Behnke et al., 2001). During the recovery period following the SNP condition, the left and right spinotrapezius muscles were superfused at an average flow rate of $\sim 1.5 \mathrm{ml} / \mathrm{min}$ with KrebsHenseleit to washout SNP. This experimental design is deemed appropriate to examine potential 
impairments in skeletal muscle hemodynamic and metabolic function following SNP superfusion given that the current washout procedure is not expected to reverse any effects of cyanideinduced toxicity with SNP (Reade et al., 2012; Way, 1984). Spinotrapezius muscle $\mathrm{PO}_{2} \mathrm{mv}$ was measured at rest and throughout contractions during all superfusion conditions. Spinotrapezius muscle blood flow and $\dot{\mathrm{V}} \mathrm{O}_{2}$ were determined at rest and during the contracting steady-state during the first and third superfusion conditions (i.e., control 1 and control 2) via radiolabeled microspheres and direct Fick calculation, respectively. In each condition, the non-stimulated left and stimulated right spinotrapezius muscles represented the resting and contracting blood flow and $\dot{\mathrm{VO}} \mathrm{O}_{2}$ measurements, respectively. Resting blood flow to individual muscles or muscle parts of the hindlimb, kidneys and organs of the splanchnic region were also measured before and after superfusion of the spinotrapezius muscle with $300 \mu \mathrm{M}$ SNP (i.e., control 1 and control 2 conditions, respectively). Preliminary investigations describing the effects of $300 \mu \mathrm{M}$ SNP superfusion on spinotrapezius muscle blood flow, $\dot{\mathrm{VO}}_{2}$ and $\mathrm{PO}_{2} \mathrm{mv}$ have been reported previously (Hirai et al., 2012; $\mathrm{n}=4$ for blood flow and $\dot{\mathrm{V}} \mathrm{O}_{2}$ and $\mathrm{n}=9$ for $\mathrm{PO}_{2} m v$ ). The current investigation provides a complete description of that work (i.e., analysis of $\mathrm{PO}_{2} \mathrm{mv}$ kinetics parameters; $\mathrm{n}=15$ ) using a larger data set along with novel measurements (blood flow to individual muscles or muscle parts of the hindlimb, kidneys and organs of the splanchnic region; $\mathrm{n}=10$ ) and experimental protocols (effects of distinct SNP superfusion concentrations on systemic (MAP) and local (spinotrapezius $\mathrm{PO}_{2} \mathrm{mv}$ ) responses. Crucial for quality control herein, a recent report from our laboratory demonstrated that the spinotrapezius preparation exhibits reproducible $\mathrm{PO}_{2} \mathrm{mv}$ profiles from three contraction bouts each separated by $\sim 30$ min (i.e., 3 min off-transition, $\sim 20$ min recovery, 3 min superfusion, 3 min incubation) with no ordering effects (Hirai et al., 2012). 
Group B. Two distinct superfusion protocols were performed to investigate whether the relevant SNP superfusion $(300 \mu \mathrm{M})$ evokes responses consistent with or approximating maximal vasodilation (i.e., marked hypotension and elevation in resting $\mathrm{PO}_{2} \mathrm{mv}$; see Fig. 1). The right spinotrapezius muscle was superfused in random order ( $5 \mathrm{ml}$ of a 300 or $1200 \mu \mathrm{M}$ SNP solution; average flow rate of $\sim 1.5 \mathrm{ml} / \mathrm{min}$ ) for a total time of $3 \mathrm{~min}$, followed by a $3 \mathrm{~min}$ incubation period (i.e., no superfusion) to allow resting MAP and muscle $\mathrm{PO}_{2} \mathrm{mv}$ to stabilize. These variables were measured and recorded and, before the second condition was initiated, the muscle was superfused for $\sim 20 \mathrm{~min}$ at an average flow rate of $\sim 1.5 \mathrm{ml} / \mathrm{min}$ with Krebs-Henseleit to wash out SNP. At the end of each experiment, rats were euthanized with intra-arterial pentobarbital sodium overdose $(\sim 50 \mathrm{mg} / \mathrm{kg})$.

\section{Measurement of blood flow}

During blood flow measurements, the tail artery catheter was connected to a $1 \mathrm{ml}$ syringe and blood withdrawal was initiated at a constant rate of $0.25 \mathrm{ml} / \mathrm{min}$ via a pump (model 907 , Harvard Apparatus, Holliston, MA, USA). Differentially radiolabeled microspheres $\left({ }^{57} \mathrm{Co}\right.$ and ${ }^{85} \mathrm{Sr}, 15 \mu \mathrm{m}$ diameter; Perkin Elmer Life and Analytical Sciences, Waltham, MA, USA) were injected in random order into the aortic arch via the carotid artery catheter during the contracting steady-state (i.e., $\sim 3$ min after the onset of muscle contractions). Upon completion of the experiment and immediately after euthanasia, the left and right spinotrapezius muscles, individual muscles or muscle parts of the hindlimb, kidneys and organs of the splanchnic region (adrenals, stomach, spleen, pancreas, small intestine, large intestine, liver) were dissected, removed and weighed. The thorax was opened and placement of the arterial catheter into the 
aortic arch was confirmed. Tissue radioactivity was determined on a gamma scintillation counter (Packard Auto Gamma Spectrometer, Cobra model 5003, Downers Grove, IL, USA) and blood flow was determined by the reference method (Ishise et al., 1980) and expressed as $\mathrm{ml} / \mathrm{min} / 100 \mathrm{~g}$ tissue. Adequate mixing of the microspheres was verified for each injection by the demonstration of a $<15 \%$ difference in blood flow between the left and right kidneys.

\section{Measurement of muscle $\mathrm{PO}_{2} \mathrm{mv}$}

Spinotrapezius $\mathrm{PO}_{2} m v$ was measured by phosphorescence quenching using a Frequency Domain Phosphorometer (PMOD 5000; Oxygen Enterprises, Philadelphia, PA, USA). The principles of the phosphorescence quenching technique have been described in detail previously (Behnke et al., 2001). Briefly, this technique applies the Stern-Volmer relationship (Rumsey et al., 1988) which describes quantitatively the $\mathrm{O}_{2}$ dependence of phosphorescent probe (R2) via the following equation:

$P O_{2} m v=\left[\left(\tau^{\circ} / \tau\right)-1\right] /\left(k_{Q} \times \tau^{\circ}\right)$

where $k_{Q}$ is the quenching constant and $\tau$ and $\tau^{\circ}$ are the phosphorescence lifetimes in the absence of $\mathrm{O}_{2}$ and the ambient $\mathrm{O}_{2}$ concentration, respectively. The phosphor $\mathrm{R} 2\left(\tau^{\circ}=601 \mu \mathrm{s}\right.$ and $k_{Q}=409 \mathrm{mmHg}^{-1} \cdot \mathrm{s}^{-1}$ at $\mathrm{pH}=7.4$ and temperature $\sim 38^{\circ} \mathrm{C}$ ) (Lo et al., 1997) was infused $\sim 15$ min prior to muscle contractions. The R2 probe binds to albumin and is distributed uniformly in the plasma, thus providing a signal corresponding to the volume-weighted $\mathrm{O}_{2}$ pressure in the microvascular compartment (primarily the $\mathrm{PO}_{2}$ within the capillaries, which volumetrically represents the major intramuscular space; Poole et al., 2004). The negative charge of the R2 
probe also facilitates its restriction to the muscle intravascular space (Poole et al., 1995). The common end of the bifurcated light guide was placed 2-4 mm superficial to the dorsal surface of the exposed right spinotrapezius muscle. The phosphorometer modulates sinusoidal excitation frequencies between $100 \mathrm{~Hz}$ and $20 \mathrm{kHz}$ and allows phosphorescence lifetime measurements from approximately $10 \mu \mathrm{s}$ to $2.5 \mathrm{~ms}$. The excitation light (524 nm; penetration depth of $\sim 500$ $\mu \mathrm{m}$ ) was focused on a randomly selected area of $\sim 2 \mathrm{~mm}$ diameter of exposed muscle and $\mathrm{PO}_{2} \mathrm{mv}$ was recorded at $2 \mathrm{~s}$ intervals throughout the duration of the experimental protocol.

$\mathrm{PO}_{2} \mathrm{mv}$ kinetics analysis

The kinetics of $\mathrm{PO}_{2} \mathrm{mv}$ during the onset of contractions were described by nonlinear regression analysis using the Marquardt-Levenberg algorithm (SigmaPlot 11.2; Systat software, San Jose, CA, USA). Transient $\mathrm{PO}_{2} m v$ responses were fit with either a one- or two-component model (Behnke et al., 2001):

One-component:

$P \mathrm{O}_{2} m v_{(t)}=P \mathrm{O}_{2} m v_{(B L)}-\Delta P O_{2} m v\left(1-e^{-(t-T D) / \tau}\right)$

Two-component:

$P O_{2} m v_{(t)}=P O_{2} m v_{(B L)}-\Delta_{1} P O_{2} m v\left(1-e^{-\left(t-T D_{1}\right) / \tau_{1}}\right)+\Delta_{2} P O_{2} m v\left(1-e^{-\left(t-T D_{2}\right) / \tau_{2}}\right)$

where $\mathrm{PO}_{2} \mathrm{mv}_{(\mathrm{t})}$ is the $\mathrm{PO}_{2} \mathrm{mv}$ at a given time $t, \mathrm{PO}_{2} \mathrm{mv}(\mathrm{BL})$ corresponds to the pre-contracting resting $\mathrm{PO}_{2} \mathrm{mv}, \Delta_{1}$ and $\Delta_{2}$ are the amplitudes for the first and second components, respectively, $\mathrm{TD}_{1}$ and $\mathrm{TD}_{2}$ are the independent time delays for each component, and $\tau_{1}$ and $\tau_{2}$ are the time 
constants (i.e., time taken to achieve $63 \%$ of the response) for each component. Goodness of fit was determined using three criteria: 1) the coefficient of determination; 2) the sum of squared residuals; and 3) visual inspection.

The mean response time (MRT; Macdonald et al., 1997) was used to describe the overall dynamics of the $\mathrm{PO}_{2} \mathrm{mv}$ fall:

$M R T=T D_{1}+\tau_{1}$

where $\mathrm{TD}_{1}$ and $\tau_{1}$ are defined above. The MRT analysis was limited to the first component of the $\mathrm{PO}_{2} \mathrm{mv}$ response given that inclusion of an emergent second component underestimates the actual speed of $\mathrm{PO}_{2} \mathrm{mv}$ fall following the onset of contractions (Hirai et al., 2009).

The area under the $\mathrm{PO}_{2} m v$ curve plotted as function of time $\left(\mathrm{PO}_{2 \mathrm{Area}}\right.$; Hirai et al., 2010) was calculated throughout each 3 min contraction protocol to provide an index of the overall spinotrapezius muscle microvascular oxygenation (i.e., incorporating resting and contracting steady-state $\mathrm{PO}_{2} \mathrm{mv}$, time delays, time constants and amplitudes of the response to yield a value expressed as $\mathrm{mmHg} \cdot \mathrm{s})$.

\section{Calculation of muscle $\dot{\mathrm{V}}{ }_{2}$}

Spinotrapezius $\dot{\mathrm{V}} \mathrm{O}_{2}$ was estimated from $\mathrm{PO}_{2} \mathrm{mv}$ and blood flow measurements as described in detail previously (Hirai et al., 2012). Briefly, arterial $\mathrm{O}_{2}$ concentration $\left(\mathrm{CaO}_{2}\right)$ was calculated from arterial blood samples whereas venous $\mathrm{O}_{2}$ concentration $\left(\mathrm{CvO}_{2}\right)$ was calculated from the resting or contracting steady-state spinotrapezius $\mathrm{PO}_{2} \mathrm{mv}$ using the rat $\mathrm{O}_{2}$ dissociation curve (Hill coefficient of 2.6), the measured hemoglobin $(\mathrm{Hb})$ concentration, a $\mathrm{P}_{50}$ of $38 \mathrm{mmHg}$, 
and an $\mathrm{O}_{2}$ carrying capacity of $1.34 \mathrm{ml} \mathrm{O}_{2} / \mathrm{g} \mathrm{Hb}$ (Altman and Dittmer, 1974). Resting and contracting steady-state spinotrapezius blood flow $(\dot{Q} m)$ values were then used to calculate $\dot{V} O_{2}$ using the Fick equation [i.e., $\left.\dot{\mathrm{V}} \mathrm{O}_{2}=\dot{\mathrm{Q}} \mathrm{m}\left(\mathrm{CaO}_{2}-\mathrm{CvO} \mathrm{O}_{2}\right)\right]$.

\section{Statistical analyses}

Data comparison was performed using paired and unpaired Student's t-test or one-way repeated measures ANOVA where appropriate. Post hoc analyses were performed with the Student-Newman-Keuls test when a significant $F$ ratio was detected. The level of significance was set at $p<0.05$. Results are presented as mean $\pm \mathrm{SE}$. 


\section{Results}

Group A: Effects of $300 \mu$ M SNP superfusion on spinotrapezius vascular and metabolic function. Before and after washout of $300 \mu \mathrm{M} \mathrm{SNP} \mathrm{(i.e.,} \mathrm{control} 1$ and control 2, respectively), spinotrapezius muscle blood flow and $\dot{V} \mathrm{O}_{2}$ increased similarly from rest to contractions $(p<0.05$ for all; Fig. 2). Importantly, there were no differences in these responses at rest and during contractions when comparing control 1 and post-washout control 2 ( $p>0.05$ for all; Fig. 2).

SNP elevated resting and contracting steady-state $\mathrm{PO}_{2} \mathrm{mv}\left(\mathrm{PO}_{2} \mathrm{mv} v_{(\mathrm{BL})}\right.$ and $\mathrm{PO}_{2} \mathrm{mv}(\mathrm{SS})$, respectively; $p<0.05$ for both; Fig. 3 and Table 1). No differences in the amplitudes and time delays of the $\mathrm{PO}_{2} \mathrm{mv}$ response were observed among conditions ( $p>0.05$ for all; Table 1$)$. The speed of $\mathrm{PO}_{2} \mathrm{mv}$ fall at the onset of contractions (as assessed by the time constant for the primary component $\left(\tau_{1}\right)$, mean response time (MRT), time to reach $63 \%$ of the primary amplitude $\left(\mathrm{T}_{63}\right)$ and relative rate of $\mathrm{PO}_{2} m v$ fall $\left.\left(\Delta_{1} \mathrm{PO}_{2} m v / \tau_{1}\right)\right)$ was markedly slowed in the SNP condition when compared to both control 1 and post-washout control 2 ( $p<0.05$ for all; Table 1). As a result, SNP elevated the overall muscle microvascular oxygenation throughout contractions $\left(P_{2 \mathrm{AREA}}\right)$ when compared to both control 1 and control 2 conditions $(p<0.05$; Table 1). Importantly, there were no differences in the $\mathrm{PO}_{2} \mathrm{mv}$ responses during the transition from rest to contractions when comparing control 1 and control 2 ( $p>0.05$ for all kinetics parameters; Table 1).

There were no differences in total resting hindlimb muscle blood flow before and after superfusion of the spinotrapezius muscle with $300 \mu \mathrm{M}$ SNP (control 1: $7 \pm 1$; control 2: $8 \pm 1$ $\mathrm{ml} / \mathrm{min} / 100 \mathrm{~g}$, respectively, $p>0.05$ ). Accordingly, 27 of 28 individual hindlimb muscles or muscle parts had similar blood flow when comparing control 1 and control 2 (exception: red gastrocnemius; Table 2). Similar blood flows to the kidneys and the majority of organs of the 
splanchnic region (exception: pancreas; Table 3) were observed when comparing control 1 and control 2.

Group B: Systemic and local effects of distinct SNP superfusion concentrations (300 and $1200 \mu M)$. Pre-SNP superfusion MAP and spinotrapezius $\mathrm{PO}_{2} \mathrm{mv}$ were not different between 300 and $1200 \mu \mathrm{M}$ conditions ( $p>0.05$ for both; Fig. 4). Spinotrapezius superfusion with $300 \mu \mathrm{M}$ SNP did not reduce MAP ( $p>0.05$ ) and elevated resting $\mathrm{PO}_{2} m v$ by $\sim 30 \%$ ( $p<0.05$; Fig. 4). Spinotrapezius superfusion with $1200 \mu \mathrm{M}$ reduced MAP by $\sim 33 \%(p<0.05)$ and increased resting $\mathrm{PO}_{2} \mathrm{mv}$ to a greater extent ( $\left.\sim 88 \%\right)$ compared to the $300 \mu \mathrm{M} \mathrm{SNP}$ concentration ( $p<0.05$; Fig. 4). Accordingly, the changes in MAP and resting $\mathrm{PO}_{2} \mathrm{mv}$ with $1200 \mu \mathrm{M}$ SNP were greater than those observed with $300 \mu \mathrm{M}$ SNP ( $p<0.05$ for both; Fig. 4). 


\section{Discussion}

Contrary to our principal hypothesis, the present investigation demonstrates that acute superfusion of the rat spinotrapezius with $300 \mu \mathrm{M}$ SNP does not precipitate residual impairment of muscle hemodynamic or metabolic control either at rest or during contractions. Improved spinotrapezius muscle microvascular oxygenation during the rest-contraction transient $\left(\mathrm{PO}_{2} \mathrm{mv}\right.$ kinetics) seen herein during the SNP bout $(300 \mu \mathrm{M})$ is consistent with that reported previously (Ferreira et al., 2006a; Ferreira et al., 2006b; Hirai et al., 2012; Hirai et al., 2010). Importantly, there were no differences in skeletal muscle blood flow, $\dot{\mathrm{VO}}{ }_{2}$ or $\mathrm{PO}_{2} \mathrm{mv}$ responses at rest or during contractions prior to superfusion and following washout of SNP (300 $\mu \mathrm{M})$. Moreover, muscle superfusion with $300 \mu \mathrm{M}$ SNP did not decrease MAP and elevated resting $\mathrm{PO}_{2} \mathrm{mv}$ to a lesser extent when compared to a four times greater concentration (1200 $\mu \mathrm{M} \mathrm{SNP})$, suggesting that $300 \mu \mathrm{M}$ SNP does not evoke responses consistent with or approximating maximal vasodilation (i.e., a ceiling effect). Such findings are indicative of preserved skeletal muscle function during transitions in metabolic demand following $300 \mu \mathrm{M}$ SNP superfusion and inconsistent with vascular or metabolic (mitochondrial) poisoning associated with cyanide accumulation and toxicity.

\section{SNP and skeletal muscle function}

SNP-induced toxicity is considered to arise primarily from cyanide release and accumulation as a product of its metabolism (Friederich and Butterworth, 1995; Ignarro et al., 2002; Pettersen and Cohen, 1993; Rao et al., 1991). Cyanide inhibits mitochondrial oxidative phosphorylation and is thus expected to lower both resting and contracting muscle $\dot{\mathrm{V}} \mathrm{O}_{2}$ (Pettersen and Cohen, 1993). In addition, cyanide accumulation may rapidly and irreversibly 
impair vasomotor control and consequently alter resting and contracting muscle blood flow (Ignarro et al., 1986). Consistent with these notions, cyanide poisoning is often used experimentally to inhibit mitochondrial respiration at cytochrome c oxidase (i.e., uncoupling agent; Shen et al., 1995; Shiva et al., 2007) and abolish vascular smooth muscle tone (e.g., Levy et al., 1993; Marano et al., 1999). These alterations, alone or in combination, are expected to disrupt the dynamic matching between muscle blood flow and $\dot{\mathrm{VO}}$ (and thus $\mathrm{PO}_{2} \mathrm{mv}$ ) particularly during the rest-contraction transient. However, unchanged muscle blood flow and $\dot{V} \mathrm{O}_{2}$ at rest and during contractions after superfusion of the spinotrapezius with $300 \mu \mathrm{M}$ SNP and subsequent washout (i.e., control 1 and control 2, respectively; Fig. 2) suggests preserved muscle vascular and mitochondrial function post-SNP washout. The possibility of prolonged and/or irreversible vasodilation secondary to SNP-induced toxicity (Ignarro et al., 1986) is not supported based on the lack of differences in resting and contracting muscle blood flow between the first and third bouts (i.e., control 1 and control 2, respectively; Fig. 2). In addition, similar spinotrapezius $\mathrm{PO}_{2} m v$ kinetics parameters and temporal profiles during the first and third bouts (i.e., control 1 and control 2, respectively; Table 1 and Fig. 3) are consistent with the notion that muscle vascular and mitochondrial function were not impaired following SNP washout.

Similar resting blood flows to the total hindlimb musculature and vast majority (27 of 28) of individual muscles or muscle parts of the hindlimb during the first and third bouts (i.e., control 1 and control 2, respectively; Table 2) provide further evidence that superfusion of the spinotrapezius with $300 \mu \mathrm{M} \mathrm{SNP}$ did not induce systemic toxicity. This notion is also supported by the finding of similar blood flows to the kidneys and most organs of the splanchnic region when comparing control 1 and control 2 (the pancreas being the only exception; Table 3). 
Taken together, these data suggest that superfusion of the spinotrapezius with $300 \mu \mathrm{M}$ SNP does not impair skeletal muscle hemodynamic and metabolic function at rest or during contractions. The apparent absence of local and systemic toxicity with the $300 \mu \mathrm{M} \mathrm{SNP}$ superfusion concentration observed herein occurred despite whatever cyanide radicals may have been released as a product of SNP metabolism (Friederich and Butterworth, 1995; Ignarro et al., 2002; Rao et al., 1991; Rauhala et al., 1998). As reviewed previously (Friederich and Butterworth, 1995; Way, 1984), cyanide from SNP reacts mainly with methemoglobin to produce cyanomethemoglobin (which is in dynamic equilibrium with cyanide and nontoxic) or thiosulfate in the liver via the catalytic action of rhodanase to produce thiocyanate (which is excreted by the kidneys). Additional pathways of cyanide detoxification include reactions with cystine (Wood and Cooley, 1956) and those catalyzed by the enzyme mercaptopyruvate sulfurtransferase (Nagahara et al., 1999), among others. Toxicity is therefore expected to occur principally: 1) with prolonged administration and/or high dosages of SNP which promote cyanide accumulation; and/or 2) in patients with some degree of renal and/or hepatic insufficiency (Friederich and Butterworth, 1995; Ignarro et al., 2002). It might be anticipated that oxidative stress mediated by SNP occurs primarily under the former circumstances. Interestingly, the SNP label introduced by the FDA in 1991 is consistent with those notions and emphasizes the risk of cyanide toxicity due to inappropriate dosages and/or extended use (Nightingale, 1991). It is important to note that the characteristics of the drug delivery method applied herein limit the potential toxic effects of cyanide accumulation from superfused SNP (see below).

It must also be acknowledged that 1) certain methods used for assaying blood cyanide concentration; and/or 2) SNP photodecomposition (which facilitates cyanide release) may overestimate the role of cyanide-induced toxicity with SNP and have promulgated the notion of 
SNP toxicity (Bisset et al., 1981; Butler et al., 1987). These aspects must be considered when utilizing the NO donor SNP in both clinical and research settings and may account, at least in part, for the controversy regarding SNP safety and reliability (Friederich and Butterworth, 1995). Thus, the lack of residual impairments in skeletal muscle function following SNP treatment demonstrated herein (Figs. 2 and 3) is consistent with the fact that appropriate administration of the NO donor SNP intravenously represents a powerful tool in the standard drug treatment of hypertension and chronic heart failure without promoting vascular and/or metabolic dysfunction (Cohn et al., 2011; Dickstein et al., 2008; Friederich and Butterworth, 1995; Ignarro et al., 2002).

It may be argued that other NO donors, such as diazeniumdiolates (e.g., spermine NONOate), could be used in an attempt to circumvent potential SNP-induced toxicity. However, heterogeneities in vasodilatory properties of NO donors must be taken into account based on the purpose of a given investigation. Contrary to SNP, spermine NONOate releases NO extracellularly and induces vasodilation via a soluble guanylate cyclase-independent mechanism, which differs from that associated with endogenous, endothelium-derived NO (Miller et al., 2004; Wanstall et al., 2001).

\section{SNP superfusion concentrations}

As noted above, the SNP superfusion concentration used herein $(300 \mu \mathrm{M})$ is similar to that used by others (Behnke and Delp, 2010; Boegehold, 1992; Didion and Mayhan, 1997; Lash and Bohlen, 1997; Muller-Delp et al., 2002; Padilla et al., 2010; Saito et al., 1994; Sato et al., 2008; Trott et al., 2009) and was established in previous investigations by titrating different doses and selecting carefully that one which elicited consistent alterations in muscle $\mathrm{PO}_{2} \mathrm{mv}$ without compromising systemic hemodynamics (i.e., $\mathrm{MAP}<70 \mathrm{mmHg}$ at any time; Behnke et al., 
2006; Ferreira et al., 2006b). The $300 \mu \mathrm{M} \mathrm{SNP}$ concentration is therefore relatively higher than that used in intra-arterial infusions or isolated tissue incubation baths due to the nature of the drug delivery method (i.e., superfusion), in which 1) considerable resistance to diffusion exists inherently; and 2) superfused chemicals are only briefly in contact with the curved dorsum of the in situ spinotrapezius as gravity directs the fluid away from the muscle to be discarded. Importantly, spinotrapezius superfusion with $300 \mu \mathrm{M}$ SNP did not decrease MAP and elevated resting $\mathrm{PO}_{2} \mathrm{mv}$ to a lesser extent when compared to $1200 \mu \mathrm{M}$ SNP (Fig. 4). These data indicate that superfusion of the rat spinotrapezius muscle with $300 \mu \mathrm{M}$ SNP increases resting $\mathrm{PO}_{2} \mathrm{mv}$ without evoking responses consistent with or approximating maximal vasodilation. The latter point is significant because it allows further vasodilation in response to muscle contractions or other mediators and does not abolish sympathetic neural control over vascular tone. As discussed previously (Ferreira et al., 2006a; Ferreira et al., 2006b; Hirai et al., 2010), the very mild hypotensive response seen herein following SNP superfusion of the spinotrapezius muscle likely derives from 'leakage' of the superfusate from within the vicinity of the muscle into the systemic circulation.

\section{Experimental considerations}

Technical limitations related to the presence of radiolabeled microspheres precluded direct cyanide measurements in resting and contracting skeletal muscle. In addition, blood samples were not taken for cyanide measurements given that the superfusion method used herein, contrary to SNP infusion, is not expected to impact systemic cyanide levels appreciably. Nonetheless, considering that SNP metabolism releases cyanide along with NO (Friederich and Butterworth, 1995), one strength of the current investigation is evaluation of potential adverse 
effects of local SNP superfusion $(300 \mu \mathrm{M})$ on resting and contracting skeletal muscle vascular and metabolic function in vivo (Group A).

Notwithstanding the synergistic and redundant nature of the multiple mechanisms regulating skeletal muscle blood flow, NO has been identified as an important component of the functional hyperemia response (e.g., Hirai et al., 1994; Schrage et al., 2004). That NO is integral to skeletal muscle $\dot{Q} \mathrm{O}_{2} / \dot{\mathrm{VO}} \mathrm{O}_{2}$ matching in health (Ferreira et al., 2006b; Hirai et al., 2010), aged (Hirai et al., 2009), disease (Ferreira et al., 2006a) and exercise trained (Hirai et al., 2012) states indicates that NO-mediated vascular and metabolic regulation in the rat spinotrapezius preparation is similar to those observed in the intact rat (Hirai et al., 1994), horse (Kindig et al., 2002) and human (Jones et al., 2003; Schrage et al., 2004).

\section{Summary and conclusions}

Utilization of NO donors such as SNP is pivotal in identifying the functional roles of NO in physiology and pathophysiology (Ignarro et al., 2002). The current investigation demonstrates that superfusion of the rat spinotrapezius with $300 \mu \mathrm{M}$ SNP does not impair skeletal muscle hemodynamic or metabolic function at rest or during contractions. Importantly, this SNP superfusion concentration elevates resting muscle $\mathrm{PO}_{2} \mathrm{mv}$ without compromising systemic hemodynamics (i.e., MAP $<70 \mathrm{mmHg}$ at any time; present results and Behnke et al., 2006; Ferreira et al., 2006b) or altering resting blood flow to the total hindlimb musculature. In addition, no differences in basal blood flow to the kidneys and majority of the organs of the splanchnic region were observed when comparing pre- and post-SNP conditions. Collectively, these observations indicate that SNP superfusion $(300 \mu \mathrm{M})$ constitutes a valid and important tool for assessing the functional roles of NO in skeletal muscle hemodynamic and metabolic control 
at rest and during contractions without incurring residual alterations consistent with cyanide accumulation and poisoning. 


\section{Acknowledgements}

The authors would like to thank K.S. Hageman and Gabrielle E. Sims for excellent technical assistance.

\section{Grants}

This project was supported in part by a Fellowship from the Brazilian Ministry of

Education/CAPES-Fulbright and a Doctoral Student Research Grant from the American College of Sports Medicine Foundation to D.M. Hirai; American Heart Association Heartland Affiliate Grant $0750090 Z$ to T.I. Musch; and Kansas State University SMILE Grant and National Institutes of Health Grant HL-108328 to D.C. Poole. 


\section{Tables}

Table 1. Spinotrapezius muscle $\mathrm{PO}_{2} \mathrm{mv}$ kinetics following the onset of contractions under three superfusion conditions performed in the following order: control 1 (Krebs-Henseleit), SNP (300 $\mu \mathrm{M})$, control 2 (Krebs-Henseleit)

\begin{tabular}{|c|c|c|c|}
\hline & Control 1 & SNP & Control 2 \\
\hline $\mathrm{PO}_{2} \mathrm{mv}_{(\mathrm{BL})}, \mathrm{mmHg}$ & $30.8 \pm 1.6$ & $42.8 \pm 3.2 *$ & $29.0 \pm 2.5$ \\
\hline$\Delta_{1} \mathrm{PO}_{2} \mathrm{mv}, \mathrm{mmHg}$ & $11.1 \pm 1.1$ & $11.9 \pm 2.5$ & $11.2 \pm 1.7$ \\
\hline$\Delta_{2} \mathrm{PO}_{2} \mathrm{mv}, \mathrm{mmHg}$ & $3.9 \pm 0.5$ & & $3.3 \pm 0.6$ \\
\hline$\Delta_{\text {Total }} \mathrm{PO}_{2} \mathrm{mv}, \mathrm{mmHg}$ & $9.0 \pm 1.2$ & $11.9 \pm 2.5$ & $9.9 \pm 1.7$ \\
\hline $\mathrm{PO}_{2} \mathrm{mv}_{(\mathrm{SS})}, \mathrm{mmHg}$ & $21.8 \pm 1.2$ & $30.9 \pm 1.9^{*}$ & $19.5 \pm 1.4$ \\
\hline $\mathbf{T D}_{1}, \mathbf{s}$ & $9.1 \pm 1.3$ & $4.9 \pm 1.3$ & $8.4 \pm 1.5$ \\
\hline $\mathbf{T D}_{2}, \mathbf{s}$ & $45.6 \pm 12.9$ & & $47.4 \pm 10.8$ \\
\hline$\tau_{1}, \mathbf{s}$ & $14.9 \pm 4.2$ & $29.5 \pm 5.8^{*}$ & $15.0 \pm 3.3$ \\
\hline$\tau_{2}, \mathbf{s}$ & $59.7 \pm 7.3$ & & $49.7 \pm 7.9$ \\
\hline MRT, s & $23.4 \pm 4.0$ & $33.6 \pm 5.7^{*}$ & $23.4 \pm 4.0$ \\
\hline $\mathbf{T}_{63}, \mathbf{s}$ & $19.8 \pm 3.2$ & $35.1 \pm 7.9^{*}$ & $20.6 \pm 2.9$ \\
\hline$\Delta_{1} P O_{2} m v / \tau_{1}, \mathrm{mmHg} / \mathrm{s}$ & $1.4 \pm 0.3$ & $0.6 \pm 0.2^{*}$ & $1.1 \pm 0.2$ \\
\hline $\mathrm{PO}_{2 \mathrm{Area}}, \mathrm{mmHg} \cdot \mathrm{s}$ & $4029 \pm 203$ & $5669 \pm 358^{*}$ & $3696 \pm 245$ \\
\hline
\end{tabular}

Values are mean \pm SE. $P_{2} m v_{(B L)}$, pre-contracting $\mathrm{PO}_{2} m v ; \Delta_{1} P_{2} m v$, amplitude of the first component; $\Delta_{2} \mathrm{PO}_{2} \mathrm{mv}$, amplitude of the second component; $\Delta_{\text {Total }} \mathrm{PO}_{2} m v$, overall amplitude regardless of one- or two-component model fit; $P O_{2} m v_{(\mathrm{SS})}$, contracting steady-state $P \mathrm{O}_{2} m v$; $\mathrm{TD}_{1}$, time delay for the first component; $\mathrm{TD}_{2}$, time delay for the second component; $\tau_{1}$, time constant for the first component; $\tau_{2}$, time constant for the second component; MRT, mean response time; $\mathrm{T}_{63}$, time to reach $63 \%$ of the primary amplitude as determined independent of modeling

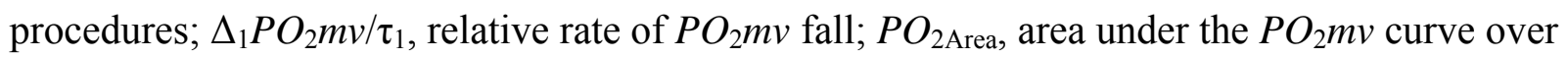
the 3 min contraction period. While the two-component exponential model was required to analyze the $\mathrm{PO}_{2} \mathrm{mv}$ kinetics in the control conditions in some instances (6 and 8 out of 15 profiles for control 1 and control 2, respectively), the one-component model was used to fit the SNP response in all cases. ${ }^{*} p<0.05$ vs. control 1 and control 2. 
Table 2. Resting blood flow ( $\mathrm{ml} / \mathrm{min} / 100 \mathrm{~g})$ to individual muscles or muscle parts of the hindlimb before and after superfusion of the spinotrapezius muscle with $300 \mu \mathrm{M}$ SNP (i.e., control 1 and control 2; respectively)

\begin{tabular}{|c|c|c|}
\hline & Control 1 & Control 2 \\
\hline \multicolumn{3}{|l|}{ Ankle extensors } \\
\hline Soleus & $15 \pm 1$ & $14 \pm 2$ \\
\hline Plantaris & $8 \pm 1$ & $9 \pm 2$ \\
\hline Gastrocnemius, red & $8 \pm 2$ & $12 \pm 3^{*}$ \\
\hline Gastrocnemius, white & $8 \pm 2$ & $7 \pm 1$ \\
\hline Gastrocnemius, mixed & $8 \pm 1$ & $8 \pm 1$ \\
\hline Tibialis posterior & $11 \pm 4$ & $14 \pm 3$ \\
\hline Flexor digitorum longus & $7 \pm 4$ & $17 \pm 5$ \\
\hline Flexor halicus longus & $7 \pm 1$ & $8 \pm 1$ \\
\hline \multicolumn{3}{|l|}{ Ankle flexors } \\
\hline Tibialis anterior, red & $8 \pm 3$ & $10 \pm 1$ \\
\hline Tibialis anterior, white & $9 \pm 2$ & $9 \pm 2$ \\
\hline Extensor digitorum longus & $9 \pm 2$ & $7 \pm 1$ \\
\hline Peroneals & $13 \pm 4$ & $11 \pm 3$ \\
\hline \multicolumn{3}{|l|}{ Knee extensors } \\
\hline Vastus intermedius & $12 \pm 2$ & $12 \pm 2$ \\
\hline Vastus medialis & $5 \pm 1$ & $6 \pm 1$ \\
\hline Vastus lateralis, red & $10 \pm 2$ & $12 \pm 1$ \\
\hline Vastus lateralis, white & $7 \pm 1$ & $9 \pm 2$ \\
\hline Vastus lateralis, mixed & $7 \pm 1$ & $7 \pm 1$ \\
\hline Rectus femoris, red & $6 \pm 1$ & $8 \pm 1$ \\
\hline Rectus femoris, white & $8 \pm 1$ & $8 \pm 1$ \\
\hline \multicolumn{3}{|l|}{$\underline{\text { Knee flexors }}$} \\
\hline Biceps femoris anterior & $6 \pm 1$ & $5 \pm 1$ \\
\hline Biceps femoris posterior & $7 \pm 1$ & $8 \pm 1$ \\
\hline Semitendinosus & $6 \pm 1$ & $8 \pm 1$ \\
\hline Semimembranosus, red & $6 \pm 1$ & $8 \pm 1$ \\
\hline Semimembranosus, white & $7 \pm 1$ & $9 \pm 1$ \\
\hline \multicolumn{3}{|l|}{ Thigh adductors } \\
\hline Adductor longus & $13 \pm 3$ & $10 \pm 3$ \\
\hline Adductor magnus \& brevis & $6 \pm 1$ & $6 \pm 1$ \\
\hline Gracilis & $7 \pm 1$ & $8 \pm 1$ \\
\hline Pectineus & $6 \pm 1$ & $7 \pm 1$ \\
\hline
\end{tabular}

Values are mean \pm SE. ${ }^{*} p<0.05$ vs. control 1. 
Table 3. Blood flow $(\mathrm{ml} / \mathrm{min} / 100 \mathrm{~g})$ to the kidneys and organs of the splanchnic region before and after superfusion of the spinotrapezius muscle with $300 \mu \mathrm{M}$ SNP (i.e., control 1 and control 2; respectively)

\begin{tabular}{lcc}
\hline \hline & Control 1 & Control 2 \\
\hline Kidneys & $480 \pm 42$ & $433 \pm 62$ \\
Adrenals & $517 \pm 63$ & $614 \pm 101$ \\
Stomach & $81 \pm 16$ & $50 \pm 6$ \\
Spleen & $166 \pm 21$ & $190 \pm 44$ \\
Pancreas & $113 \pm 19$ & $61 \pm 14^{*}$ \\
Small intestine & $295 \pm 27$ & $277 \pm 16$ \\
Large intestine & $129 \pm 14$ & $105 \pm 6$ \\
Liver $\dagger$ & $31 \pm 10$ & $34 \pm 4$ \\
\hline
\end{tabular}

Values are mean \pm SE. ${ }^{*} p<0.05$ vs. control 1. †Designates arterial, not portal, blood flow and vascular conductance. 


\section{References}

Altman, P. L., Dittmer, D. S., 1974. Biology Data Book. FASEB, Bethesda, MD.

Bailey, J. K., et al., 2000. Spinotrapezius muscle microcirculatory function: effects of surgical exteriorization. Am J Physiol Heart Circ Physiol. 279, H3131-7.

Behnke, B. J., et al., 2002. Dynamics of oxygen uptake following exercise onset in rat skeletal muscle. Respir Physiol Neurobiol. 133, 229-39.

Behnke, B. J., Delp, M. D., 2010. Aging blunts the dynamics of vasodilation in isolated skeletal muscle resistance vessels. J Appl Physiol. 108, 14-20.

Behnke, B. J., et al., 2001. Dynamics of microvascular oxygen pressure across the rest-exercise transition in rat skeletal muscle. Respir Physiol. 126, 53-63.

Behnke, B. J., et al., 2006. Effects of arterial hypotension on microvascular oxygen exchange in contracting skeletal muscle. J Appl Physiol. 100, 1019-26.

Bisset, W. I., et al., 1981. Sodium nitroprusside and cyanide release: reasons for re-appraisal. $\mathrm{Br}$ J Anaesth. 53, 1015-8.

Boegehold, M. A., 1992. Reduced influence of nitric oxide on arteriolar tone in hypertensive Dahl rats. Hypertension. 19, 290-5.

Butler, A. R., et al., 1987. Further investigations regarding the toxicity of sodium nitroprusside. Clin Chem. 33, 490-2.

Cohn, J. N., et al., 2011. Direct-acting vasodilators. J Clin Hypertens (Greenwich). 13, 690-2.

Dickstein, K., et al., 2008. ESC Guidelines for the diagnosis and treatment of acute and chronic heart failure 2008: the Task Force for the Diagnosis and Treatment of Acute and Chronic Heart Failure 2008 of the European Society of Cardiology. Developed in collaboration with the Heart Failure Association of the ESC (HFA) and endorsed by the European Society of Intensive Care Medicine (ESICM). Eur Heart J. 29, 2388-442.

Didion, S. P., Mayhan, W. G., 1997. Effect of chronic myocardial infarction on in vivo reactivity of skeletal muscle arterioles. Am J Physiol. 272, H2403-8.

Ferreira, L. F., et al., 2006a. Muscle microvascular oxygenation in chronic heart failure: role of nitric oxide availability. Acta Physiol (Oxf). 188, 3-13.

Ferreira, L. F., et al., 2006b. Effects of altered nitric oxide availability on rat muscle microvascular oxygenation during contractions. Acta Physiol (Oxf). 186, 223-32.

Friederich, J. A., Butterworth, J. F. t., 1995. Sodium nitroprusside: twenty years and counting. Anesth Analg. 81, 152-62.

Hirai, D. M., et al., 2012. Exercise training and muscle microvascular oxygenation: functional role of nitric oxide. J Appl Physiol. 113, 557-65.

Hirai, D. M., et al., 2010. Nitric oxide bioavailability modulates the dynamics of microvascular oxygen exchange during recovery from contractions. Acta Physiol (Oxf). 200, 159-69.

Hirai, D. M., et al., 2009. Aging impacts microvascular oxygen pressures during recovery from contractions in rat skeletal muscle. Respir Physiol Neurobiol. 169, 315-22.

Hirai, T., et al., 1994. Effects of NO synthase inhibition on the muscular blood flow response to treadmill exercise in rats. J Appl Physiol. 77, 1288-93.

Ignarro, L. J., et al., 1986. Dissimilarities between methylene blue and cyanide on relaxation and cyclic GMP formation in endothelium-intact intrapulmonary artery caused by nitrogen oxide-containing vasodilators and acetylcholine. J Pharmacol Exp Ther. 236, 30-6.

Ignarro, L. J., et al., 2002. Nitric oxide donors and cardiovascular agents modulating the bioactivity of nitric oxide: an overview. Circ Res. 90, 21-8. 
Ishise, S., et al., 1980. Reference sample microsphere method: cardiac output and blood flows in conscious rat. Am J Physiol. 239, H443-H449.

Jones, A. M., et al., 2003. Inhibition of nitric oxide synthase by L-NAME speeds phase II pulmonary $\dot{\mathrm{V}} \mathrm{O}_{2}$ kinetics in the transition to moderate-intensity exercise in man. J Physiol. $552,265-72$.

Kindig, C. A., et al., 2002. Nitric oxide synthase inhibition speeds oxygen uptake kinetics in horses during moderate domain running. Respir Physiol Neurobiol. 132, 169-78.

Lash, J. M., Bohlen, H. G., 1997. Time- and order-dependent changes in functional and NOmediated dilation during exercise training. J Appl Physiol. 82, 460-8.

Levy, B. I., et al., 1993. Role of endothelium in the mechanical response of the carotid arterial wall to calcium blockade in spontaneously hypertensive and Wistar-Kyoto rats. J Hypertens. 11, 57-63.

Lo, L. W., et al., 1997. A new, water soluble, phosphor for oxygen measurements in vivo. Adv Exp Med Biol. 428, 651-6.

Macdonald, M., et al., 1997. Acceleration of $\dot{V} \mathrm{O}_{2}$ kinetics in heavy submaximal exercise by hyperoxia and prior high-intensity exercise. J Appl Physiol. 83, 1318-25.

Marano, G., et al., 1999. Endothelin and mechanical properties of the carotid artery in WistarKyoto and spontaneously hypertensive rats. Cardiovasc Res. 41, 701-7.

Miller, M. R., et al., 2004. Extracellular nitric oxide release mediates soluble guanylate cyclaseindependent vasodilator action of spermine NONOate: comparison with other nitric oxide donors in isolated rat femoral arteries. J Cardiovasc Pharmacol. 43, 440-51.

Muller-Delp, J. M., et al., 2002. Aging impairs endothelium-dependent vasodilation in rat skeletal muscle arterioles. Am J Physiol Heart Circ Physiol. 283, H1662-72.

Nagahara, N., et al., 1999. Mercaptopyruvate sulfurtransferase as a defense against cyanide toxication: molecular properties and mode of detoxification. Histol Histopathol. 14, 1277-86.

Nightingale, S. L., 1991. From the Food and Drug Administration. JAMA. 265, 847.

Padilla, J., et al., 2010. Relationship between brachial and femoral artery endothelial vasomotor function/phenotype in pigs. Exp Biol Med (Maywood). 235, 1287-91.

Pettersen, J. C., Cohen, S. D., 1993. The effects of cyanide on brain mitochondrial cytochrome oxidase and respiratory activities. J Appl Toxicol. 13, 9-14.

Poole, D. C., et al., 2004. Measurement of muscle microvascular oxygen pressures: compartmentalization of phosphorescent probe. Microcirculation. 11, 317-26.

Poole, D. C., et al., 1995. Diaphragm microvascular plasma $\mathrm{PO}_{2}$ measured in vivo. J Appl Physiol. 79, 2050-7.

Rao, D. N., et al., 1991. Reductive metabolism of nitroprusside in rat hepatocytes and human erythrocytes. Arch Biochem Biophys. 286, 30-7.

Rauhala, P., et al., 1998. Apparent role of hydroxyl radicals in oxidative brain injury induced by sodium nitroprusside. Free Radic Biol Med. 24, 1065-73.

Reade, M. C., et al., 2012. Review article: management of cyanide poisoning. Emerg Med Australas. 24, 225-38.

Robin, E. D., McCauley, R., 1992. Nitroprusside-related cyanide poisoning. Time (long past due) for urgent, effective interventions. Chest. 102, 1842-5.

Rumsey, W. L., et al., 1988. Imaging of phosphorescence: a novel method for measuring oxygen distribution in perfused tissue. Science. 241, 1649-51. 
Saito, Y., et al., 1994. Role of EDRFs in the control of arteriolar diameter during increased metabolism of striated muscle. Am J Physiol. 267, H195-200.

Sato, K., et al., 2008. Vasodilation of intramuscular arterioles under shear stress in dystrophindeficient skeletal muscle is impaired through decreased nNOS expression. Acta Myol. 27, 30-6.

Schrage, W. G., et al., 2004. Local inhibition of nitric oxide and prostaglandins independently reduces forearm exercise hyperaemia in humans. J Physiol. 557, 599-611.

Shen, W., et al., 1995. Nitric oxide. An important signaling mechanism between vascular endothelium and parenchymal cells in the regulation of oxygen consumption. Circulation. 92, 3505-12.

Shiva, S., et al., 2007. Deoxymyoglobin is a nitrite reductase that generates nitric oxide and regulates mitochondrial respiration. Circ Res. 100, 654-61.

Stamler, J. S., Meissner, G., 2001. Physiology of nitric oxide in skeletal muscle. Physiol Rev. 81, 209-237.

Trott, D. W., et al., 2009. Exercise training reverses age-related decrements in endotheliumdependent dilation in skeletal muscle feed arteries. J Appl Physiol. 106, 1925-34.

Varon, J., Marik, P. E., 2003. Clinical review: the management of hypertensive crises. Crit Care. 7, 374-84.

Wanstall, J. C., et al., 2001. Vascular smooth muscle relaxation mediated by nitric oxide donors: a comparison with acetylcholine, nitric oxide and nitroxyl ion. Br J Pharmacol. 134, 46372.

Way, J. L., 1984. Cyanide intoxication and its mechanism of antagonism. Annu Rev Pharmacol Toxicol. 24, 451-81.

Wood, J. L., Cooley, S. L., 1956. Detoxication of cyanide by cystine. J Biol Chem. 218, 449-57. 


\section{Figure legends}

Figure 1

Group A

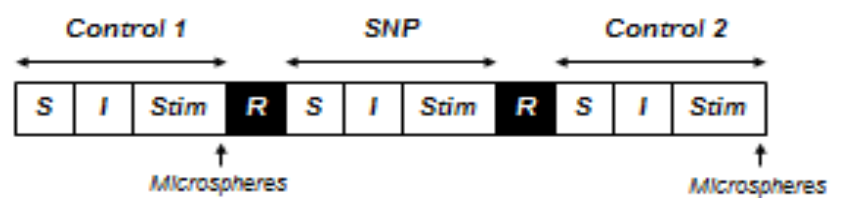

Group B

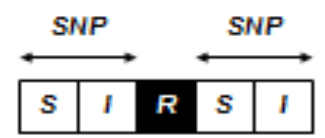

Fig. 1 Schematic representation of the experimental protocol (diagram not to scale). Group A: Control 1 (Krebs-Henseleit), SNP (300 $\mu$ M SNP), Control 2 (Krebs-Henseleit). Group B: 300 or $1200 \mu \mathrm{M}$ SNP superfusion in random order. S, superfusion (3 min); I, incubation (3 min); Stim, electrical stimulation of the right spinotrapezius muscle (3 min); R, recovery and washout ( $\sim 20$ $\min )$. See text for further details. 
Figure 2
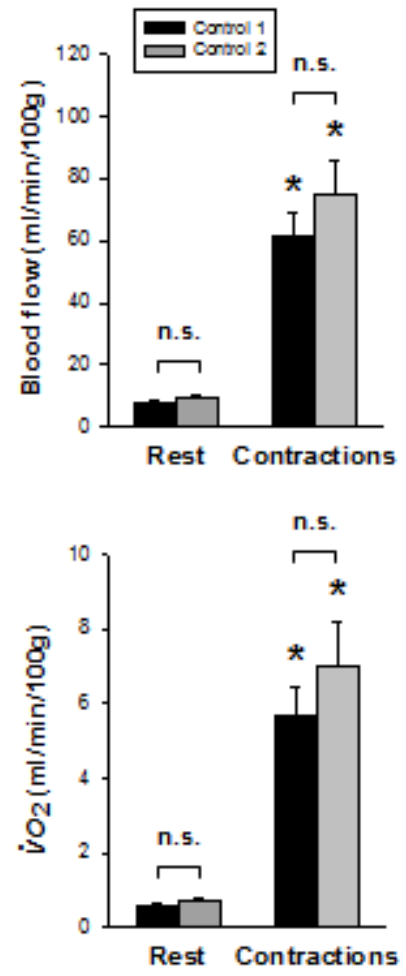

Fig. 2 Spinotrapezius muscle blood flow (top panel) and $\dot{\mathrm{V}} \mathrm{O}_{2}$ (bottom panel) at rest and during the contraction steady-state before and after superfusion with $300 \mu \mathrm{M}$ SNP (i.e., control 1 and control 2, respectively). Three contraction bouts were performed in the following order: control 1(Krebs-Henseleit), SNP $(300 \mu \mathrm{M})$, control 2 (Krebs-Henseleit). Note similar spinotrapezius muscle blood flow and $\dot{\mathrm{V}} \mathrm{O}_{2}$ responses between control 1 and control 2 both at rest and during the contraction steady-state ( $p>0.05$ for all). n.s., not significantly different; ${ }^{*} p<0.05$ vs. rest. 
Figure 3
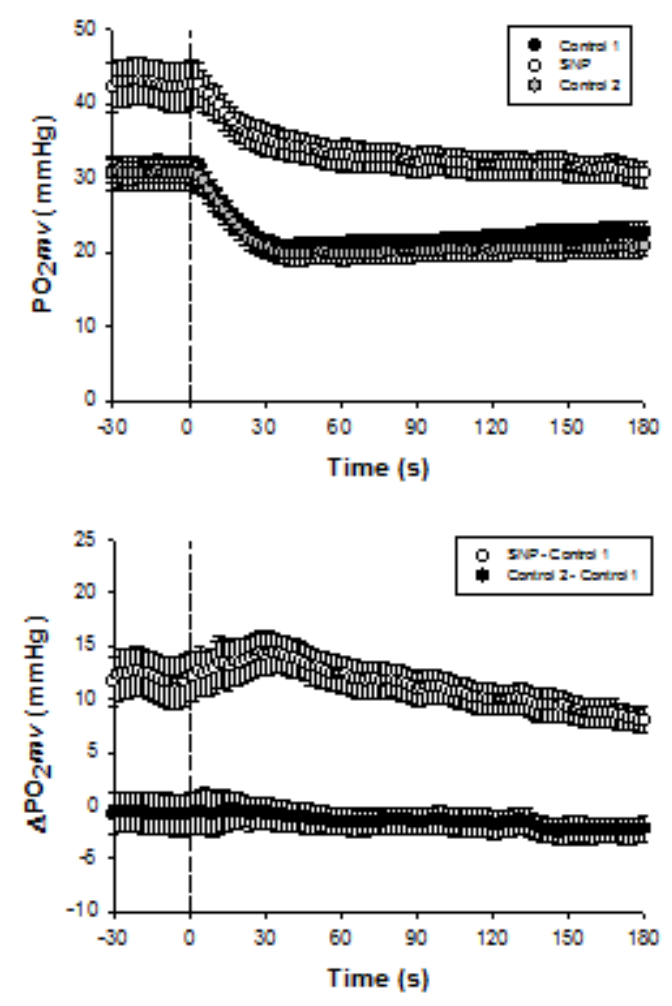

Fig. 3 Top panel depicts the spinotrapezius muscle $\mathrm{PO}_{2} \mathrm{mv}$ at rest and during the onset of contractions under distinct superfusion conditions performed in the following order: control 1 (Krebs-Henseleit), SNP (300 $\mu \mathrm{M})$, control 2 (Krebs-Henseleit). Bottom panel further illustrates the change in muscle $\mathrm{PO}_{2} \mathrm{mv}$ with $300 \mu \mathrm{M}$ SNP (elevated resting and contracting steady-state $\mathrm{PO}_{2} \mathrm{mv}$ along with slower speed of $\mathrm{PO}_{2} \mathrm{mv}$ fall at contractions onset, see Table 1) and the similarity between control 1 and control 2 ( $p>0.05$ for all kinetics parameters, see Table 1$)$. Time zero denotes the onset of muscle contractions. See text for further details. 
Figure 4
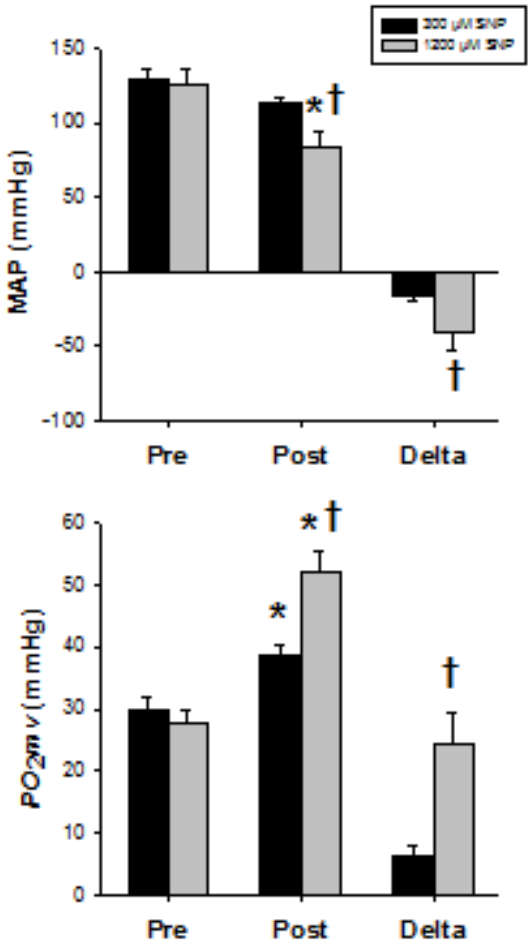
Fig. 4 Effects of distinct SNP superfusion concentrations (300 and $1200 \mu \mathrm{M}$ ) on resting MAP (top panel) and spinotrapezius muscle $\mathrm{PO}_{2} \mathrm{mv}$ (bottom panel). Note that a four times greater concentration of SNP $(1200 \mu \mathrm{M})$ evoked greater effects on both resting MAP and $\mathrm{PO}_{2} \mathrm{mv}$ when compared to the SNP concentration used currently in our and other laboratories (Behnke and Delp, 2010; Boegehold, 1992; Didion and Mayhan, 1997; Ferreira et al., 2006a; Ferreira et al., 2006b; Hirai et al., 2012; Hirai et al., 2010; Lash and Bohlen, 1997; Muller-Delp et al., 2002;

Padilla et al., 2010; Saito et al., 1994; Sato et al., 2008; Trott et al., 2009). Pre, pre-superfusion; post, post-superfusion; delta, difference between pre- and post-superfusion. ${ }^{*} p<0.05$ vs. presuperfusion within SNP concentration. $† p<0.05$ vs. $300 \mu \mathrm{M}$ SNP within condition. 